\title{
The association between physical fitness and depressive symptoms among young adults: results of the Northern Finland 1966 birth cohort study
}

Kadri Suija ${ }^{1,2^{*}}$, Markku Timonen ${ }^{1}$, Maarit Suviola ${ }^{1}$, Jari Jokelainen ${ }^{1,3}$, Marjo-Riitta Järvelin ${ }^{4,5}$ and Tuija Tammelin ${ }^{6,7}$

\begin{abstract}
Background: The effect of physical activity on mental health has been the subject of research for several decades. However, there is a lack of studies investigating the association between physical fitness, including both cardiorespiratory and muscular fitness and depressive symptoms among general population. The aim of this study was to determine the association between physical fitness and depressive symptoms among young adults.

Methods: The study population consists of 5497 males and females, members of the Northern Finland birth cohort of 1966, who at age 31 completed fitness tests and filled in a questionnaire including questions about depressive symptoms (Hopkins' Symptom Checklist-25) and physical activity. Cardiorespiratory fitness was measured by a 4-min step test and muscular fitness by tests of maximal isometric handgrip and isometric trunk extension. The odds ratios (OR) with $95 \%$ confidence intervals $(95 \% \mathrm{Cl}$ ) for having depressive symptoms were calculated for quintiles groups of physical fitness using the third, median quintile as reference group, and the results were adjusted for potential confounding variables.

Results: Depressive symptoms were most common among males and females in the lowest quintile group of trunk extension test (OR 1.58 and $95 \% \mathrm{Cl}$ 1.07-2.32 in males and $\mathrm{OR} 1.43$ and $95 \% \mathrm{Cl}$ 1.03-2.0 in females) and among males in the lowest quintile group of handgrip strength (OR $1.6495 \% \mathrm{Cl} 1.11-2.42)$ compared to the reference group. Level of self-reported physical activity was inversely associated with depressive symptoms both in males (OR 1.74 95\% Cl 1.25-2.36) and females (OR 1.36 95\% Cl 1.05-1.75). The cardiorespiratory fitness was not associated with depressive symptoms (OR 1.01 95\% Cl 0.68-1.49 in males and 0.82 95\% Cl 0.57-1.16 in females).

Conclusions: The results indicate that low level of isometric endurance capacity of trunk extensor muscles is associated with high level of depressive symptoms in both sexes. In males, also poor handgrip strength is associated with increased levels of depressive symptoms. The physical activity level is inversely associated with the prevalence of depressive symptoms among young adults.
\end{abstract}

Keywords: Physical fitness, Physical activity, Cardiorespiratory fitness, Muscular fitness, Depressive symptoms, Depression, Young adults

\footnotetext{
*Correspondence: kadri.suija@ut.ee

'Institute of Health Sciences, University of Oulu, Box 5000, FIN 90014, Oulu,

Finland

${ }^{2}$ Department of Family Medicine, University of Tartu, Puusepa 1a, 50406

Tartu, Estonia

Full list of author information is available at the end of the article
} 


\section{Background}

The effect of physical activity on mental health has been the subject of research for several decades. Epidemiological studies of community samples have demonstrated that greater amounts of physical activity are generally associated with reduced depressive symptoms [1-4]. In addition, the large population-based study has also presented an inverse graded dose-response relationship between maximal cardiorespiratory fitness and depressive symptoms [2]. There are also studies about depressive symptoms and other physical fitness measurements. For example the Netherlands Study of Depression and Anxiety showed that women with depressive disorder had lower handgrip strength in comparison with healthy women [5]. Similarly some aging studies have found negative associations between handgrip strength and depression [6]. Further, individuals who are physically more fit, are also less likely to be concurrently diagnosed as having clinical depression [7-10].

The interpretation of the results of different earlier studies concerning the association between physical fitness/ activity and depressive symptoms is hampered because of several methodological discrepancies in the study designs and case definitions for both depression or depressive symptoms and physical activity. To the best of our knowledge, epidemiological studies examining physical activity and depressive symptoms have used questionnaires and structured interviews for measuring physical activity and depressive symptoms. None of the large epidemiological studies have investigated the association between physical fitness including both cardiorespiratory and muscular fitness and depressive symptoms in young adults. Objective measurements of physical fitness would provide complimentary information to self-reported physical activity and fitness [11].

The aims of the current study were to determine the cross-sectional associations between: 1) physical activity and depressive symptoms, and 2) physical fitness, including both cardiorespiratory and muscular fitness and depressive symptoms among young adults. We suggested that low levels of physical fitness and physical activity are associated with higher prevalence of depressive symptoms among young adults.

\section{Methods}

\section{Study population}

The study population consisted of the Northern Finland birth cohort of 1966, originally including all 12231 males and females whose expected year of birth was 1966 [12]. In 1997-1998, at age 31, all the members of the cohort who were still alive $(\mathrm{N}=11541)$ were invited to participate in a follow-up survey. A questionnaire including questions about depressive symptoms and physical activity was mailed to this group, and 8767 (76\%) persons responded. The subjects who were living in the Northern Finland, or had moved to the Helsinki capital area, were also invited to a medical examination performed in local health centres. The invitation to participate in the medical examination was accepted by 6033 persons $(71 \%$ of those invited), and 5497 (65\% of those invited) males and females completed all fitness tests. Altogether 51\% of them were women, $73 \%$ were married or cohabiting and $71 \%$ were employed.

The Ethics Committee of Oulu University Hospital has approved this study. Written informed consent was obtained from all the subjects before participation in the study.

\section{Variables}

\section{Depressive symptoms}

Information on depressive symptoms was obtained through Hopkins' Symptom Checklist-25 (HSCL-25) [13-17] which was included in the above-mentioned postal questionnaires. HSCL-25 is a 25 -item shortened version of an originally 90 -item questionnaire designed by Derogatis et al. [13]. A depression subscale consists of 13 items $[13,14,17]$. Cohort members recorded their estimates of severity of their depressive symptoms on a scale ranging from 1 ("not at all") to 4 ("extremely"). Responses were summed and divided by the number of answered items to generate a depressive symptoms mean score ranging from 1.0 to 4.0. There are two commonly used mean scores of 1.55 and 1.75 [13,14,17]. These points are cut off points for important depressive symptoms but not for diagnosis of major depression.

\section{Physical fitness}

Four teams of trained research nurses, who supervised the fitness tests and performed the anthropometric measurements, carried out the medical examinations. Before the fitness test, the subjects were interviewed to screen out persons with cardiovascular diseases or orthopaedic problems. Less than $10 \%$ of all subjects were excluded from the analyses for various reasons. The most common reasons for not performing step or trunk extension tests at this age of 31 years were ill health and pregnancy [18].

\section{Cardiorespiratory fitness}

In the medical examination, the subjects performed a submaximal four-minute single step test conducted without shoes on a bench $33 \mathrm{~cm}$ high for the females and $40 \mathrm{~cm}$ high for the males [19]. We used heart rate after step test as an indicator of cardiorespiratory fitness. A metronome paced a rate of 23 steps per minute. Heart rate (beats $\mathrm{min}^{-1}$ ) was measured immediately after the test by a heart rate monitor handle on the chest (Fitwatch, Polar Electro, Kempele, Finland). In a laboratory measurements of 123 adults aged 31 years the correlation coefficient between heart rate after step test and peak 
oxygen uptake during maximal exercise test was $0.53[19]$.

\section{Muscular fitness}

Muscular fitness was measured by trunk extension test and maximal isometric handgrip test. During the trunk extension test $[18,20]$ the subject was in a prone position, the lower body lying on the stand and the upper body unsupported from the level of the anterior superior iliac spine upwards. The tester sitting on them stabilized the legs and the arms were held beside the trunk. The isometric endurance capacity of the trunk extensor muscles was evaluated by holding the upper part of the body in a horizontal position as long as possible, however, not exceeding four minutes. When the subject was no longer able to maintain the horizontal position, the test ended. The outcome measure of the test was the endurance time in seconds.

Maximal isometric handgrip strength of the dominant hand was measured with a hand dynamometer (Newtest, Oulu, Finland) based on the strain-gauge technique. Measurements were performed with the subject in a standing position, holding the dynamometer, with the hand beside but not touching the trunk. The wrist and the elbow were extended. The width of the grip in the dynamometer was adjusted to the size of the hand. The highest value in Newton $(\mathrm{N})$ of the three trials, each lasting from two to four seconds, was accepted as the result [18].

\section{Leisure-time physical activity}

In the above-mentioned postal questionnaires, subjects were also asked how often they participated in light and brisk physical activities. Response alternatives in this study were daily, four to six times a week, two to three times a week, once a week, two to three times a month, and once a month or less often. The duration of one bout of activity was considered separately for light and brisk activities with the following alternatives: more than 90 minutes, $60-90$ minutes, $40-59$ minutes, 20-39 minutes, less than 20 minutes, and not at all. In the questionnaire, the term 'brisk' was defined as physical activity causing at least some sweating and getting out of breath, and the term 'light' as physical activity causing no sweating or getting out of breath. Total volume of leisure-time physical activity was expressed as metabolic equivalent hours/ week (MET-hours/week), which was formed by calculating duration and frequency of both brisk and light physical activity. In the calculations, an intensity value of 3 METs was used for light physical activity and 5 METs for brisk physical activity. We formed five equally distributed categories to describe quintiles of physical activity (Q1-Q5) (Table 1).
Table 1 Prevalence of depressive symptoms according to quintiles groups of cardiorespiratory fitness, muscular fitness and physical activity

\begin{tabular}{cc}
\hline Male & Female \\
\hline HSCL-25 - 1.75 & HSCL-25 - 1.75 \\
\hline$\%(95 \% \mathrm{Cl})$ & $\%(95 \% \mathrm{Cl})$ \\
\hline
\end{tabular}

Cardiorespiratory fitness, heart rate after step test, beats/min

$\begin{array}{llll}\text { Q1 (161-197) } & 11.4(8.9-14.4) & \text { Q1 (166-199) } & 13.2(10.5-16.4) \\ \text { Q2 (152-160) } & 8.5(6.3-11.2) & \text { Q2 (157-165) } & 15.4(12.6-18.7) \\ \text { Q3 (143-151) } & 10.6(8.4-13.4) & \text { Q3 (148-156) } & 15.6(12.9-18.8) \\ \text { Q4 (134-142) } & 11.3(8.8-14.4) & \text { Q4 (137-147) } & 17.1(14.2-20.5) \\ \text { Q5 (76-133) } & 7.8(5.9-10.4) & \text { Q5 (74-136) } & 17.9(15.0-21.3) \\ & \text { P }=0.163^{*} & & P=0.255^{*}\end{array}$

Muscular fitness, trunk extension test, $\mathrm{s}$

\begin{tabular}{cccc} 
Q1 (1-120) & $14.8(12.1-18.0)$ & Q1 (10-125) & $20.7(17.6-24.2)$ \\
Q2 (121-147) & $11.3(8.9-14.3)$ & Q2 (126-165) & $17.3(14.3-20.7)$ \\
Q3 (148-177) & $10.3(8.0-13.2)$ & Q3 (166-211) & $14.6(11.9-17.8)$ \\
Q4 (178-214) & $6.7(4.9-9.1)$ & Q4 (212-240) & $13.8(11.9-16.0)$ \\
Q5 (215-240) & $7.5(5.5-10.0)$ & & \\
& P $<0.001^{*}$ & & $P=0.002^{*}$ \\
\hline
\end{tabular}

Muscular fitness, handgrip test, kg

$\begin{array}{lccc}\text { Q1 (15.8-42.4) } & 14.4(11.7-17.6) & \text { Q1 (3.3-23.6) } & 15.1(12.5-18.2) \\ \text { Q2 (42.5-47.5) } & 10.9(8.6-13.8) & \text { Q2 (23.7-26.6) } & 15.2(12.5-18.3) \\ \text { Q3 (47.6-51.7) } & 9.4(7.2-12.1) & \text { Q3 (26.7-29.3) } & 16.7(13.9-19.9) \\ \text { Q4 (51.8-56.3) } & 8.6(6.5-11.3) & \text { Q4 (29.4-32.3) } & 15.7(13.0-18.9) \\ \text { Q5 (56.4-99.0) } & 8.0(6.0-10.6) & \text { Q5 (32.4-90.5) } & 18.5(15.6-21.8) \\ & \text { P }=0.004^{*} & & P=0.485^{*}\end{array}$

Physical activity, MET-hours/week

\begin{tabular}{cccc} 
Q1 ( 1.6$)$ & $17.9(15.4-20.7)$ & Q1 $(\leq 3.7)$ & $21.3(18.8-24.0)$ \\
Q2 (1.7-7.4) & $11.3(9.3-13.8)$ & Q2 (3.8-9.4) & $18.9(16.4-21.6)$ \\
Q3 (7.5-13.7) & $9.6(7.8-11.8)$ & Q3 (9.5-15.5) & $15.7(13.4-18.3)$ \\
Q4 (13.8-26.1) & $9.5(7.7-11.8)$ & Q4 (15.6-26.1) & $15.0(12.8-17.4)$ \\
Q5 (26.2-84.0) & $8.8(7.0-11.0)$ & Q5 (26.2-84.0) & $15.7(13.3-18.3)$ \\
& P $<0.001^{*}$ & & $\mathrm{P}=0.001^{*}$ \\
\hline
\end{tabular}

HSCL-25 = Hopkins' Symptom Checklist-25, cut-off point 1.75 . $95 \% \mathrm{Cl}=95 \%$ confidence interval.

$\mathrm{MET}=$ metabolic equivalent.

$\mathrm{Q}=$ quintile of corresponding physical activity or fitness variable.

"Chi-Square-test p-values.

\section{Potential confounding variables}

Since alcohol intake, obesity, smoking and somatic diseases have been shown to be associated with depressive symptoms [21-23] and physical fitness [24,25], those were used as potential confounding factors in multivariate regression analyses.

\section{Alcohol intake}

Information on the frequencies of beer, wine and other spirit consumptions as well as statements on the usual amounts of each alcoholic drink per one drinking occasion 
was requested in the questionnaire. For each type of drink (the alcohol percentages of which were turned into amounts of pure alcohol consumed), the frequency of alcohol use was proportioned to 365 days. The average amount of pure alcohol (g/day) was calculated as follows: pure alcohol (g) at any one time $\mathrm{x}$ frequency of alcohol use (1/day). Alcohol consumption was categorized as abstainers/light drinkers $(<15 \mathrm{~g}$ of pure alcohol/day), moderate drinkers (15-40 g/day), and heavy drinkers (> $40 \mathrm{~g} /$ day) [26].

\section{Obesity}

Body mass index (BMI) was calculated as weight $/$ height $^{2}$ $\left(\mathrm{kg} \cdot \mathrm{m}^{-2}\right)$. Body height and weight were measured to an accuracy of $0.1 \mathrm{~cm}$ and $0.1 \mathrm{~kg}$, respectively.

\section{Smoking}

Cohort member's regular daily smoking at the age of 31 was classified as follows: regular smokers (i.e. smoking on 7 days a week), occasional smokers, (i.e. smoking less than on 7 days per week) and non-smokers [27].

\section{Somatic diseases}

We used data of national Finnish hospital discharge register about the presence of lifetime hospital-treated somatic disease [28].

\section{Statistical methods}

The prevalence of depressive symptoms (as defined by the HSCL-25 depression subscale mean score cut off points of 1.55 and 1.75) was compared in quintiles groups of physical activity and fitness (Q1-Q5). In order to adjust the results for potential confounding variables, multiple binary logistic regression analyses were used. Odds ratios (OR) with $95 \%$ confidence intervals $(95 \% \mathrm{CI})$ were calculated for having depressive symptoms by different quintiles of physical activity and fitness. The third quintile group (Q3) was used as reference group.

All statistical analyses were performed using the statistical program Stata (Stata Statistical Software: Release 11. StataCorp. 2009. College Station, TX: StataCorp LP.).

\section{Results}

The prevalence of depressive symptoms as defined by the HSCL-25 depression subscale mean score of 1.55 and 1.75 in males was $18.2 \%$ and $11.7 \%$, respectively. The corresponding numbers for females were $26.0 \%$ and 17.4\%. The results were similar (no significant differences) by using different cut-off values (1.55 or 1.75) and therefore only results for cut-off score 1.75 are presented in tables.

The prevalence of depressive symptoms in quintile groups of physical activity and fitness are presented in Table 1 . The prevalence of depressive symptoms increased in line with decreasing result of trunk extension test in both genders. For example, 14.8\% of males and 20.7\% of females in the lowest quintile and $7.5 \%$ in the highest quintile had depressive symptoms. Results of the handgrip test were related with depressive symptoms in males $(\mathrm{p}=0.004)$ but not in females $(\mathrm{p}=0.485)$. The physical activity level (MET-hours/week) was inversely associated with the prevalence of depressive symptoms in both genders, but cardiorespiratory fitness was not associated with depressive symptoms in either males or females.

The results after adjusting for potential confounding factors (alcohol intake, smoking, obesity, somatic diseases) are presented in Table 2. The third quintile (Q3) of each variable was used as the reference group (ref). Regarding the trunk extension test, the ORs of depressive symptoms in the lowest quintile was 1.58 (95\% CI, 1.07-2.32) for males and 1.43 (95\% CI, 1.03-2.0) for females. Concerning the handgrip test, the ORs of depressive symptoms in the lowest quintile was 1.64 (95\% CI, 1.11-2.42) in males and 0.86 (95\% CI, 0.63-1.18) in females.

The lowest quintile of physical activity $(\leq 1.6$ METhours/week) associated with increased likelihood of depressive symptoms in males: OR was 1.74 (95\% CI, $1.25-2.36)$. In females, the two lowest quintiles ( $\leq 9.4$ METhours/week) associated with depressive symptoms as defined by cut-off point of 1.75 ORs being up to 1.36 (95\% CI, 1.05-1.75).

With regard to cardiorespiratory fitness, the highest quintile associated with decreased level of depressive symptoms $(\mathrm{OR}=0.65,95 \% \mathrm{CI}$ 0.42-1.0) in males using the HSCL-25 cut-off point of 1.75 .

\section{Discussion}

Our study shows that high level of isometric endurance capacity of trunk extensor muscles is associated with low levels of depressive symptoms in both males and females. In males, also poor handgrip strength was associated with increased levels of depressive symptoms. Our results are consistent with previous research showing the association between handgrip strength and depressive symptoms [5,6]. However, these earlier studies have been conducted among middle-aged or elderly population. Therefore, the present study provides new information about the inverse association between muscular fitness and depressive symptoms also among young adults.

We also found that the low level of self-reported physical activity was significantly associated with increased prevalence of depressive symptoms among young adults. The association between depressive symptoms and low level of self-reported physical activity has already been shown in several previous studies [1-3].

Interestingly, there was no significant association between objectively measured cardiorespiratory fitness and 
Table 2 Multivariate logistic regression analysis of depressive symptoms using Hopkins' Symptom Checklist-25

\begin{tabular}{|c|c|c|c|c|}
\hline & \multicolumn{4}{|c|}{ Depressive symptoms (HSCL-25 - 1.75) } \\
\hline & \multicolumn{2}{|c|}{ Male } & \multicolumn{2}{|c|}{ Female } \\
\hline & Crude & Adjusted $^{*}$ & Crude & Adjusted $^{*}$ \\
\hline & OR $(95 \% \mathrm{Cl})$ & OR $(95 \% \mathrm{Cl})$ & OR $(95 \% \mathrm{Cl})$ & OR $(95 \% \mathrm{Cl})$ \\
\hline \multicolumn{5}{|c|}{ Cardiorespiratory fitness, heart rate after step test, beats/min } \\
\hline Q1 & $1.08(0.74-1.57)$ & $1.01(0.68-1.49)$ & $0.82(0.59-1.15)$ & $0.82(0.57-1.16)$ \\
\hline Q2 & $0.78(0.52-1.17)$ & $0.8(0.53-1.21)$ & $0.99(0.72-1.36)$ & $1.01(0.72-1.4)$ \\
\hline Q3 & ref. & ref. & ref. & ref. \\
\hline Q4 & $1.07(0.73-1.57)$ & $1.05(0.71-1.56)$ & $1.12(0.82-1.53)$ & $1.18(0.85-1.63)$ \\
\hline Q5 & $0.72(0.48-1.07)$ & $0.65(0.42-1.0)$ & $1.18(0.87-1.6)$ & $1.24(0.9-1.71)$ \\
\hline \multicolumn{5}{|c|}{ Muscular fitness, trunk extension test, s } \\
\hline 21 & $1.52(1.05-2.18)$ & $1.58(1.07-2.32)$ & $1.53(1.12-2.08)$ & $1.43(1.03-2.0)$ \\
\hline Q2 & $1.11(0.75-1.64)$ & $1.07(0.71-1.61)$ & $1.22(0.88-1.69)$ & $1.13(0.81-1.58)$ \\
\hline Q3 & ref. & ref. & ref. & ref. \\
\hline Q4 & $0.62(0.4-0.97)$ & $0.66(0.42-1.04)$ & $0.94(0.7-1.25)$ & $0.96(0.71-1.29)$ \\
\hline Q5 & $0.7(0.46-1.08)$ & $0.74(0.48-1.16)$ & $(-)$ & $(-)$ \\
\hline
\end{tabular}

\begin{tabular}{lcccc}
\hline \multicolumn{4}{l}{ Muscular fitness, handgrip test, kg } & \\
Q1 & $1.63(1.12-2.36)$ & $1.64(1.11-2.42)$ & $0.89(0.65-1.21)$ & $0.86(0.63-1.18)$ \\
Q2 & $1.18(0.8-1.75)$ & $1.25(0.83-1.87)$ & $0.89(0.66-1.22)$ & $0.87(0.63-1.19)$ \\
Q3 & ref. & ref. & ref. & ref. \\
Q4 & $0.91(0.6-1.38)$ & $1(0.66-1.54)$ & $0.93(0.68-1.26)$ & $0.88(0.64-1.21)$ \\
Q5 & $0.84(0.55-1.29)$ & $0.87(0.56-1.35)$ & $1.13(0.84-1.52)$ & $1.08(0.8-1.47)$ \\
\hline
\end{tabular}

Physical activity, MET-hours/week

Q1 $2.05(1.53-2.75) \quad 1.74(1.29-2.36) \quad 1.45(1.14-1.85) \quad 1.36(1.05-1.75)$

Q2 $1.2(0.87-1.65) \quad 1.1(0.79-1.53) \quad 1.25(0.97-1.61) \quad 1.3(1.0-1.7)$

Q3 ref. ref. ref. ref.

Q4 $0.99(0.71-1.38) \quad 0.96(0.68-1.35) \quad 0.94(0.73-1.22) \quad 0.99(0.76-1.29)$

Q5 $0.91(0.65-1.27) \quad 0.92(0.65-1.31) \quad 1(0.77-1.3) \quad 1.05$ (0.8-1.38)

HSCL-25 = Hopkins' Symptom Checklist-25, cut-off point 1.75 .

$\mathrm{OR}=$ Odds ratio.

$95 \% \mathrm{Cl}=95 \%$ confidence interval

$\mathrm{MET}=$ metabolic equivalent.

$\mathrm{Q}=$ quintile of corresponding physical activity or fitness variable.

"adjusted to potential confounding variables (alcohol intake, smoking, obesity, somatic diseases).

depressive symptoms in either males or females. These results are not consistent with the evidence from the first community-based observational study demonstrating the inverse association between maximal cardiorespiratory fitness and depressive symptoms [2] in which participants completed a maximal exercise treadmill test to estimate cardiorespiratory fitness. However, in our study, we used submaximal step test to measure cardiorespiratory fitness. The main reason we performed submaximal exercise test was that direct measurement of maximum oxygen consumption (VO2max) during a maximal exercise test is time-consuming, requires laboratory equipment and involves health risks especially in large populations. The use of different measurement methods (submaximal vs. maximal exercise test) may explain the differences in the results regarding cardiorespiratory fitness.

On the other hand, in our study, muscular fitness was measured by maximal trunk extension test and maximal handgrip test. It may be that the results from physical fitness tests that need maximal physical effort and at the same time maximal mental motivation to perform the test maximally are more strongly associated with depressive symptoms. This maximal or submaximal physical effort needed during the certain fitness test may explain why results of the submaximal step test were not associated with depressive symptoms.

Major depressive disorder is a highly prevalent condition that worsens functioning and quality of life [29]. Furthermore, the number of people diagnosed as having depressive disorder is rising [30]. The identification of prevention and invention strategies aimed at decreasing depressive symptom, which can be applied to populations inexpensively and without side effects, would be needed. In clinical practice, physical activity and subsequent good physical fitness inevitably have potential benefits with very few obvious risks. Physical activity is a particularly beneficial behaviour due to the combined effects on both physical and mental health $[1,9]$. Several mechanisms, how exercise affects depressive symptoms, have been proposed. We speculate that physical inactivity is likely to be both a cause and consequence of depressive symptoms. As depression can be characterized by low energy, it is possible that depression leads to decreased physical activity and physical fitness. People who are depressed may be less likely to engage in physical activities [31,32] and, on the other hand, good mental health increases likelihood of engaging in physical activity [33]. However, there are also studies showing no effect of exercise on depressive symptoms [34]. According to the recent systematic review, the effectiveness of exercise on treatment of major depression is still unknown [35]. Even causality between depressive symptoms and physical activity/fitness could not be evaluated; our study presents associations with several different measures of physical fitness.

\section{Study limitations and strengths}

Limitations of our study are the cross-sectional nature of these data that does not allow inferences about causality. Further, the HSCL-25 does not provide a specific depression diagnosis like structured clinical interviews. The weakness of the study is also that we used selfreported leisure-time physical activity. In addition, cardiorespiratory fitness was measured by using the submaximal step test and not by a maximal exercise test, which is regarded more accurate test to evaluate cardiorespiratory fitness. 
The strengths of our study were that it was based on a large representative sample $(\mathrm{N}=5497)$ of young (31 years) people born in the North of Finland. Extensive data based on the general population, describing people of different socioeconomic classes, offers a unique opportunity to study the association between depressive symptoms and physical fitness. Additionally, HSCL-25 has proved to be an acceptable screening scale for obtaining information on symptoms of depression among large population [15].

Even we used self-reported questionnaire to determine physical activity, objective measurements of muscular fitness by maximal tests can be considered strength of this study.

\section{Conclusions}

Our novel finding was that a low level of isometric endurance capacity of trunk extensor muscles is associated with high level of depressive symptoms in both sexes. In males, also poor handgrip strength was associated with increased levels of depressive symptoms. The physical activity level was inversely associated with the prevalence of depressive symptoms among young adults. Further investigations are needed to clarify gender differences and whether it is specifically the maximal effort needed in physical fitness test that explains the observed association between poor results in maximal fitness test and depressive symptoms.

\section{Abbreviations}

OR: Odds Ratio; 95\% Cl: 95\% Confidence interval; MET: Metabolic equivalent; N: Newton; BMI: Body mass index; HSCL-25: Hopkins' Symptom Checklist-2; ref: Reference group; V02max: Maximum oxygen consumption.

\section{Competing interest}

The authors declare that they have no competing interests.

\section{Authors' contributions}

KS interpreted the results and drafted the manuscript. MT participated in the design of the study and investigation. MS analysed the data and helped to draft the manuscript. JJ performed the statistical analysis. MRJ participated in the design of the study. $\pi$ conceived of the study and participated in its design. All authors participated in the write-up, contributed to the interpretation of the study results and approved the final version of the manuscript submitted for publication. All authors read and approved the final manuscript.

\section{Acknowledgments}

The work was done in the Institute of Health Sciences, University of Oulu, Oulu, Finland.

\footnotetext{
Author details

${ }^{1}$ Institute of Health Sciences, University of Oulu, Box 5000, FIN 90014, Oulu, Finland. ${ }^{2}$ Department of Family Medicine, University of Tartu, Puusepa 1a, 50406, Tartu, Estonia. ${ }^{3}$ Unit of General Practice, Oulu University Hospital, FIN 90029, Oulu, Finland. ${ }^{4}$ National Public Health Institute, P.O. Box 310, FIN 90101, Oulu, Finland. ${ }^{5}$ Imperial College, London, UK. ' LIKES - Research Center for Sport and Health Sciences, Viitaniementie 15aFIN 40720, Jyväskylä, Finland. ${ }^{7}$ Finnish Institute of Occupational Health, Aapistie 1FIN 90220, Oulu, Finland.
}

Received: 25 January 2013 Accepted: 30 May 2013

Published: 3 June 2013

\section{References}

1. Farmer ME, Locke BZ, Moscicki EK, Dannenberg AL, Larson DB, Radloff LS: Physical activity and depressive symptoms: the NHANES I Epidemiologic Follow-up Study. Am J Epidemiol 1988, 128:1340-1351.

2. Galper DI, Trivedi MH, Barlow CE, Dunn AL, Kampert JB: Inverse association between physical inactivity and mental health in men and women. Med Sci Sports Exerc 2006, 38:173-178.

3. Kritz-Silversteind, Barrett-Connor $E_{1}$ Corbeau C: Cross-sectional and prospective study of exercise and depressed mood in the elderly: the Rancho Bernardo Study. Am J Epidemiol 2001, 153:596-603.

4. Vallance JK, Winkler EA, Gardiner PA, Healy GN, Lynch BM, Owen N: Associations of objectively-assessed physical activity and sedentary time with depression: NHANES (2005-2006). Prev Med 2011, 53:284-288.

5. van Millingen BA, Lamers F, de Hoop GT, Smit JH, Penninx BWJH: Objective physical functioning in patients with depressive and/or anxiety disorder. Journal of Affective Disordes 2011, 131:193-199.

6. Rantanen T, Penninx BW, Masaki K, Lintunen T, Foley D, Guralnik JM: Depressed mood and body mass index as predictors of muscle strength decline in old men. J Am Geriatr Soc 2000, 48(6):613-617.

7. Goodwin RD: Association between physical activity and mental disorders among adults in the United States. Prev Med 2003, 36:698-703.

8. Paffenbarger RS, Lee IM, Leung R: Physical activity and personal characteristics associated with depression and suicide in American college men. Acta Psychiatr Scand 1994, 377:16-22.

9. Strawbridge WJ, Deleger S, Roberts RE, Kaplan GA: Physical activity reduces the risk of subsequent depression for older adults. Am J Epidemiol 2002, 156:328-334.

10. Weyerer S: Physical inactivity and depression in the community. Evidence from the Upper Bavarian Field Study. Int J Sports Med 1992, 13:492-496

11. Kempen Gl, van Heuvelen MJ, van den Brink RH, Kooijman AC, Klein M, Houx PJ, Ormel J: Factors affecting contrasting results between self-reported and performance-based levels of physical limitation. Age Ageing 1996, 25(6):458-464.

12. Rantakallio P: The longitudinal study of the Northern Finland birth cohort of 1966. Paediatr Perinat Epidemiol 1998, 2:59-88.

13. Derogatis LR, Lipman RS, Covi C: SCL-90: an outpatients psychiatric rating scale- preliminary report. Psychopharmacol Bull 1973, 9:13-27.

14. Nettelbladt P, Hansson L, Stefansson CG, Borgquist L, Nordstrom G: Test characteristics of the Hopkins Symptom Checklist-25 (HSCL-25) in Sweden, using the Present State Examination (PSE-9) as a caseness criterion. Soc Psychiatry Psychiatr Epidemiol 1993, 28:130-133.

15. Sandanger I, Moum T, Ingebrigtsen G, Dalgard OS, Sörensen T, Bruusgaard $D$ : Concordance between symptom screening and diagnostic procedure: the Hopkins Symptom Checklist-25 and the composite international diagnostic interview I. Soc Psychiatry Psychiatr Epidemiol 1998, 33:345-354.

16. Timonen M, Jokelainen J, Hakko H, Silvennoinen-Kassinen S, Meyer-Rochow VB, Herva A, Räsänen P: The Association Between Atopy and Depression: The Northern Finland 1966 Birth Cohort Study. Mol Psychiatry 1966, 2003(8):738-744.

17. Winokur A, Winokur DF, Rickels K, Cox DS: Symptoms of emotional distress in a family planning service: Stability over a four-week period. $\mathrm{Br} J$ Psychiatry 1984, 144:395-399.

18. Tammelin $T$, Näyhä S, Rintamäki $H$, Zitting P: Occupational physical activity is related to physical fitness in young workers. Med Sci Sports Exerc 2002, 34:158-166

19. Tammelin T, Näyhä S, Rintamäki H: Cardiorespiratory fitness of males and females of northern Finland birth cohort of 1966 at age 31. Int J Sports Med 2004, 25:547-552.

20. Biering-Sörensen F: Physical measurements as risk indicators for low-back trouble over a one-year period. Spine 1984, 9:106-119.

21. Breslau N, Kilbey MM, Andreski P: Nicotine dependence and major depression. New evidence from a prospective investigation. Arch Gen Psychiatry 1993, 50:31-35.

22. Roberts RE, Kaplan GA, Shema SJ, Strawbridge WJ: Are the obese at greater risk for depression? Am J Epidemiol 2000, 152:163-170.

23. Roy A, DeJong J, Lamparski D, George T, Linnoila M: Depression among alcoholics. Relationship to clinical and cerebrospinal fluid variables. Arch Gen Psychiatry 1991, 48:428-432.

24. Haenle MM, Brockmann SO, Kron M, Bertling U, Mason RA, Steinbach G, Boehm BO, Koenig W, Kern P, Piechotowski I, Kratzer W, EMIL-Study group: 
Overweight, physical activity, tobacco and alcohol consumption in a cross-sectional random sample of German adults. BMC Public Health 2006, 6:233.

25. Pitsavos $P$, Panagiotakos DB, Lentzas $Y$, Stefanadis C: Epidemiology of leisure-time physical activity in socio-demographic, lifestyle and psychological characteristics of men and women in Greece: the ATTICA Study. BMC Public Health 2005, 5:37.

26. Sillanaukee $P$, Massot $N$, Jousilahti $P$, Vartiainen $E$, Poikolainen $K$, Olsson $U$, Alho $\mathrm{H}$ : Enhanced clinical utility of $\mathrm{\gamma}$-CDT in a general population. Alcohol Clin Exp Res 2000, 24:1202-1206.

27. Liukkonen T, Silvennoinen-Kassinen $\mathrm{S}$, Jokelainen J, Räsänen $\mathrm{P}$, Leinonen $\mathrm{M}$, Meyer-Rochow BV, Timonen M: The Association between C-reactive protein (CRP) levels and Depression: The Northern Finland, 1966 Birth Cohort Study. Biol Psychiatry 1966, 2006(60):825-830

28. Liukkonen $T$, Räsänen $P$, Jokelainen J, Leinonen $M$, Järvelin $M R$, Meyer-Rochow VB, Timonen M: The association between anxiety and C-reactive protein (CRP) levels: Results from the Northern Finland, 1966 Birth Cohort Study. Eur Psychiatry 1966, 2011(26):363-369.

29. Alonso J, Angermeyer MC, Bernert S, Bruffaerts R, Brugha TS, Bryson H, de Girolamo G, Graaf R, Demyttenaere K, Gasquet I, Haro JM, Katz SJ, Kessler RC, Kovess V, Lepine JP, Ormel J, Polidori G, Russo LJ, Vilagut G, Almansa J, Arbabzadef-Bouchez S, Autonell J, Bernal M, Buist-Bouwman MA, Codony M, Domingo-Salvany A, Ferrer M, Joo SS, Martinez-Alonso M, Matschinger H, Mazzi F, Mrgan Z, Morosini P, Palacin C, Romera B, Taub N, Vollebergh WA, ESEMeD/MHEDEA 2000 Investigators, European Study of the Epidemiology of Mental Disorders (ESEMeD) Project: Disability and quality of life impact of mental disorders in Europe: results from the European Study of Epidemiology of Mental Disorders (ESEMeD) project. Acta Psychiatr Scand Suppl 2004, 420:38-46.

30. Klerman GL, Weissman MM: Increasing rates of depression. JAMA 1989, 261:2229-2235.

31. Suija K, Pechter Ü, Kalda R, Tähepõld H, Maaroos J, Maaroos HI: Physical activity of depressed patients and their motivation to exercise: Nordic Walking in family practice. Int J Rehabil Res 2009, 32:132-138.

32. Paluska SA, Schwenk TL: Physical activity and mental health: current concepts. Sports Med 2000, 29:167-180.

33. Dunn AL, Trivedi MH, O'Neal HA: Physical activity dose-response effects on outcomes of depression and anxiety. Med Sci Sports Exerc 2001, 33(6 Suppl):S587-597.

34. Chalder M, Wiles NJ, Campbell J, Hollinghurts SP, Haase A, Taylor AH, Fox KR, Costelloe C, Searle A, Baxter H, Winder R, Wright C, Turner KM, Calnan M, Lawlor DA, Peters TJ, Sharp DJ, Motgomery AA, Lewis G: Facilitated physical activity as a treatment for depressed adults: randomized controlled trial. BMJ 2012, 344:e2758.

35. Cipriani A, Barbui C, Butler R, Hatcher S, Geddes J: Depression in adults: drug and physical treatments. Clin Evid (Online) 2011, 25:pii:1003.

\section{Submit your next manuscript to BioMed Central and take full advantage of:}

- Convenient online submission

- Thorough peer review

- No space constraints or color figure charges

- Immediate publication on acceptance

- Inclusion in PubMed, CAS, Scopus and Google Scholar

- Research which is freely available for redistribution

Submit your manuscript at www.biomedcentral.com/submit
Ciomed Central 